\title{
Qumran und die Archäologie
}

\author{
Texte und Kontexte \\ Hrsg. v. Jörg Frey, Carsten Claußen u. Nadine Kessler
}

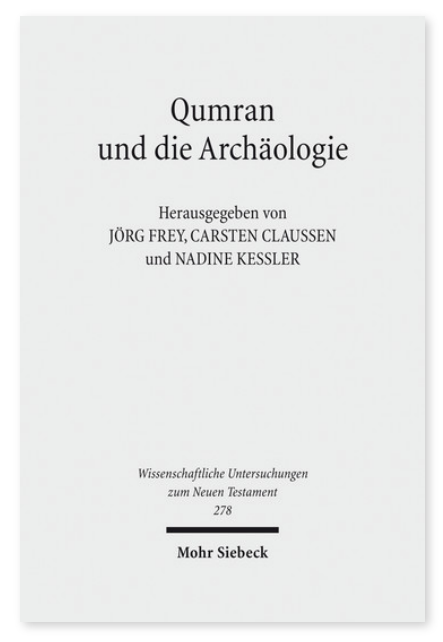

2011. XI, 561 Seiten. WUNT I 278

ISBN 978-3-16-151777-8 DOI 10.1628/978-3-16-151777-8 eBook PDF 159,00€

ISBN 978-3-16-150840-0

Leinen $159,00 €$
In der Diskussion um die Funde von Qumran ist in den letzten Jahren verstärkt die Archäologie in den Blick getreten. Verbreitete Ansichten zum Charakter der Siedlung von Khirbet Qumran und zur Funktion der Gebäude wurden in Frage gestellt, und teilweise wurde der Bezug zwischen den Schriftrollen und der Siedlung selbst in Zweifel gezogen. Dieser Band, der im Kern auf eine Fachtagung im Frühjahr 2008 zurückgeht, will das Gespräch zwischen Textwissenschaft und archäologischer Kontextforschung beleben. Erörtert werden wissenschaftstheoretische Fragen der Verbindung von Archäologie und Textforschung, neuere Erkenntnisse zur Archäologie von Khirbet Qumran und seiner Umgebung, der Charakter und die Zusammengehörigkeit der »Bibliothek « von Qumran, aber auch in Qumran gefundene Artefakte sowie in einzelnen Qumran-Texten vorliegende architektonische Vorstellungen, um zu einer präziseren Bestimmung des Verhältnisses zwischen den textlichen Welten und der »Außenwelt« zu kommen.

Inhaltsübersicht

I. Einführung: Jörg Frey: Qumran und die Archäologie. Eine Einführung - Carsten Claußen: Die Identifizierung der Grabungsstätte Khirbet Qumran. Eine forschungsgeschichtliche Annäherung - Dieter Vieweger: Text und (Be-)Fund. Archäologie und Exegese als Geschichtswissenschaften - Sabine Hüttig : Archäologie versus Textforschung? Versuch einer Aufarbeitung gegenwärtiger Kontroversen in der Erforschung von Khirbet Qumran

II. Archäologische Kontexte:

Jürgen Zangenberg: Zwischen Zufall und Einzigartigkeit. Bemerkungen zur jüngsten Diskussion über die Funktion von Khirbet Qumran und die Rolle einiger ausgewählter archäologischer Befunde - Jan A. Gunneweg : Qumran vis-à-vis Science-based Archaeology: How to go about? - Joan E. Taylor und Shimon Gibson: Qumran Connected: The Qumran pass and Paths of the North-Western Dead Sea - Jonathan Ben-Dov: The Qumran Dial: Artifact, Text, and Context - Mladen Popovic: The Roman Destruction of Qumran Revisited - Friedrich Schipper und Anne Lykke : Qumran und Jericho (Tulul Abu el-Alayiq) III. Die Texte und die Bibliothek:

Danie/ Stökl Ben Ezra: Wie viele Bibliotheken gab es in Qumran? - Devorah Dimant: The Vocabulary of the Qumran Sectarian Texts

IV. Architektur und »Außenwelt":

Simone Paganini : Von Ezechiel bis zur Tempelrolle: Der Tempel als Realität und Vision - Johann Maier: Ideale Planungsziele und Realarchitektur in der Tempelrolle und an der herodianischen Tempelanlage - Hugo Antonissen: The Visionary Architecture of New Jerusalem in Qumran - Craig A. Evans: Hanging and Crucifixion in Second Temple Israel. Deuteronomy 21:22-23 in the Light of Archaeology and the Dead Sea Scrolls - Michael Tilly: Tod und Trauer in der Tempelrolle und im rabbinischen Judentum

Carsten Claußen Geboren 1966; Dr. theol., ist Pastor der Evangelisch-Freikirchlichen Gemeinde in Frankfurt a. M. und Habilitand im Fach Neues Testament.

Jörg Frey Geboren 1962; 1996 Promotion; 1998 Habilitation; Professur für neutestamentliche Wissenschaft mit den Schwerpunkten Antikes Judentum und Hermeneutik an der Theologischen Fakultät der Universität Zürich und Research Associate der University of the Free State, Bloemfontein/ZA.

https://orcid.org/0000-0001-6628-8834

Nadine Kessler Geboren 1979; ist wissenschaftliche Mitarbeiterin an der Theologischen Fakultät der Universität Zürich.

Jetzt bestellen:

https://mohrsiebeck.com/buch/qumran-und-die-archaeologie-9783161517778?no_cache=1

order@mohrsiebeck.com

Telefon: $+49(0) 7071-923-17$

Telefax: +49 (0)7071-51104 